\title{
Experimental study on pot-cover effect under unidirectional freezing-thawing cycle
}

\author{
Chen Han ${ }^{\text {i) }}$, Luo Ting* ${ }^{\text {ii)}}$, Chen Wei ${ }^{\text {iii) }}$ \\ i) Ph.D Student, School of Transportation Science and Engineering, Beihang University, 37, Xueyuan Road, Beijing 100191, China. \\ ii) Professor, Ditto. \\ iv) Master Student, Ditto.
}

\begin{abstract}
An experiment has been carried out to study the soil moisture increasing characteristics caused by Pot-cover Effect under unidirectional freezing-thawing cycle. After 30 freezing-thawing cycles, frost heave and thaw settlement has occurred in the soil sample. The results of temperature and water content monitoring indicate that the moisture of the soil sample increase significantly and the water content of the top soil reaches nearly liquid limit. It is also observed that the freezing front move down gradually with the number of the cycle increases. The test results show that freezing-thawing cycle can accelerate the increase of soil moisture caused by Pot-cover Effect.
\end{abstract}

Keywords: pot-cover effect; unidirectional freezing-thawing cycle; vapor transfer

\section{INTRODUCTION}

Shenyang Taoxian International Airport of China have experienced significant runway disasters in recent years (Fig.1). During the maintenance, a large amount of water flow out of the gravel layer under the pavement (Fig.2) (Luo et al., 2019). As Shenyang is located in the semi-arid area, the water cannot come from rainfall or groundwater, but from the 'Pot-cover Effect'. Thus, it can be seen that the effect will cause significant moisture accumulation of the subgrade soil. According to the related research of constitutive theory for soils, the deformation of soils is influenced not only by the stress (Yao et al., 2009; Yao et al., 2008a; Yao et al., 2008b; Yao et al., 2013), but also by the variation of water content (Gao et al., 2010; Guo et al., 2013; Sun et al., 2007a; Sun et al., 2007b; Sun et al., 2007c). Therefore, the Pot-cover Effect can cause a series of engineering diseases, like uneven settlement, frost heave and frost boil etc. The study of Pot-cover Effect is of great significance.

Much attention was paid to the effect in recent years. Yao and Wang (2018) studied the prevention measures of the engineering diseases caused by Pot-cover Effect through the numerical simulation method. Luo et al. (2019) developed the test apparatus and verified its function by a series of experiments. Luo et al. (2019) buried sensors in Beijing New Airport and monitor the water content and temperature under a cover, the field test results proved that the soil moisture under the cover will increase because of Pot-cover Effect. Zhang et al. (2016) verified that vapor flow apparently contributes to ice formation by a series of laboratory freezing experiments. Teng et al. (2018) did a series of laboratory experiments and the results showed that significant moisture accumulation occurred in relatively dry specimens when the temperature at the cover drops below the freezing. It can be seen that the researches have been focused on the vapor transfer under the constant temperature gradient. However, the temperature change mode is mostly freezing-thawing cycle in practical engineering, so we need to study vapor transfer characteristics under freezing-thawing cycle conditions.

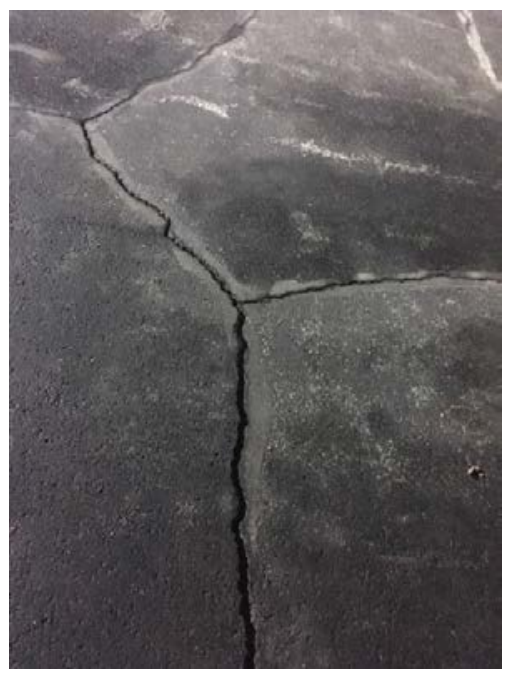

(a) cracking on runway 


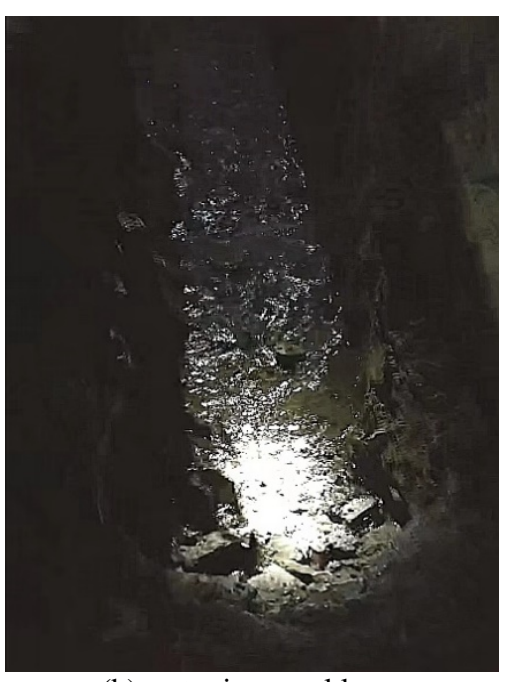

(b) water in gravel layer

Fig.1. Engineering disaster of Shenyang Taoxian International Airport.

\section{SOIL MATERIAL AND ESTING APPARATUS}

The soil studied is silty clay which comes from Beijing New Airport. Table 1 and Figure 2 is physical parameters and particle size distribution curve of the soil material, respectively.

Table 1. Physical parameters of the soil material.

\begin{tabular}{cccccc}
\hline $\begin{array}{c}\text { Soil } \\
\text { species }\end{array}$ & $\begin{array}{c}\text { Liquid } \\
\text { limit } \\
/ \%\end{array}$ & $\begin{array}{c}\text { Plastic } \\
\text { limit } \\
/ \%\end{array}$ & $\begin{array}{c}\text { Maximum } \\
\text { dry density } \\
/ \mathrm{g} / \mathrm{cm}^{3}\end{array}$ & $\begin{array}{c}\text { Optimum } \\
\text { moisture } \\
\text { content } / \%\end{array}$ & $\begin{array}{c}\text { Specific } \\
\text { gravity of } \\
\text { soil } \\
\text { particle }\end{array}$ \\
\hline $\begin{array}{c}\text { Silty } \\
\text { clay }\end{array}$ & 30.44 & 16.47 & 2.0 & 18.5 & 2.71 \\
\hline
\end{tabular}

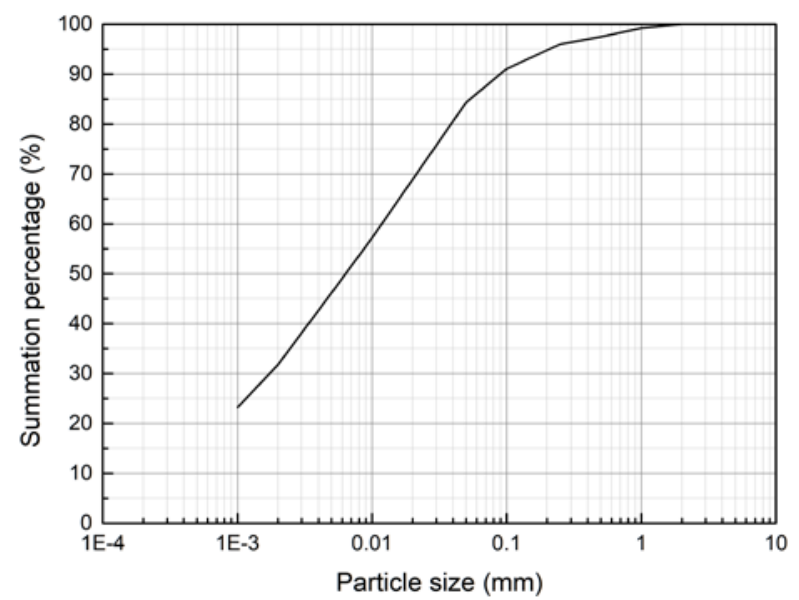

Fig.2. Particle size distribution curve of the silty clay.

The test was carried out in Pot-cover Effect Apparatus with Freezing-thawing Cycles (Figure 3), which was developed by Beihang University of China. The cylinder can contain soil samples with a height of $58 \mathrm{~cm}$ and a diameter of $30 \mathrm{~cm}$. Distilled water is supplied by a Mariotte bottle to the soil. The temperatures of the upper and lower soil boundary are controlled by two temperature-control plate which connect two thermostats. The monitor system consists of 12 sensors and a data logger, which can monitor the temperature and water content of the soil sample in real-time. The sensors are buried in the soil, Table 2 is the depth of each sensor.

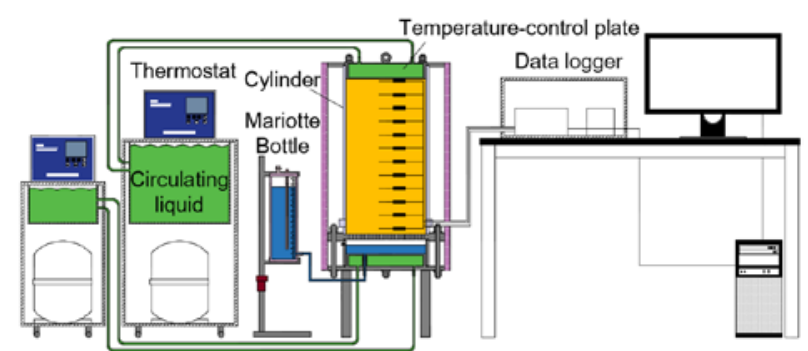

Fig.3. Schematic diagram of Pot-cover Effect Apparatus with Freezing-thawing Cycles.

Table 2. Depth of the sensors in the soil sample.

\begin{tabular}{cc}
\hline Sensor number & Depth/cm \\
\hline 1 & 2 \\
2 & 4 \\
3 & 6 \\
4 & 8 \\
5 & 10 \\
6 & 15 \\
7 & 20 \\
8 & 25 \\
9 & 30 \\
10 & 35 \\
11 & 45 \\
12 & 55 \\
\hline
\end{tabular}

Table 3 and 4 show is initial conditions of the soil samples and test scheme, respectively. The cycle period is 7 days and total cycle times is 30 . The freezing period is $1 \sim 6$ days with a temperature of $-20{ }^{\circ} \mathrm{C}$ and the thawing period is the $7^{\text {th }}$ day with a temperature of $20{ }^{\circ} \mathrm{C}$, which formats unidirectional freezing-thawing cycle condition.

Table 3. Initial conditions of the soil samples.

\begin{tabular}{cccccc}
\hline $\begin{array}{c}\text { Dry } \\
\text { density } \\
/ \mathrm{g} / \mathrm{cm}^{3}\end{array}$ & $\begin{array}{c}\text { Volumetric } \\
\text { water } \\
\text { content } / \%\end{array}$ & $\begin{array}{c}\text { Porosity } \\
/ \%\end{array}$ & $\begin{array}{c}\text { Void } \\
\text { ratio }\end{array}$ & $\begin{array}{c}\text { Ambient } \\
\text { temperature } \\
/{ }^{\circ} \mathrm{C}\end{array}$ & $\begin{array}{c}\text { Soil } \\
\text { temperature } \\
/{ }^{\circ} \mathrm{C}\end{array}$ \\
\hline 1.2 & 12 & 55.8 & 1.26 & 20 & 20 \\
\hline
\end{tabular}

Table 4. Test scheme.

\begin{tabular}{cccccc}
\hline $\begin{array}{c}\text { Cycle } \\
\text { times }\end{array}$ & $\begin{array}{c}\text { Cycle } \\
\text { period/D }\end{array}$ & $\begin{array}{c}\text { Freezing } \\
\text { period/D }\end{array}$ & $\begin{array}{c}\text { Thawing } \\
\text { period/D }\end{array}$ & $\begin{array}{c}\text { Freezing } \\
\text { temperature } /{ }^{\circ} \mathrm{C}\end{array}$ & $\begin{array}{c}\text { Thawing } \\
\text { temperature } /{ }^{\circ} \mathrm{C}\end{array}$ \\
\hline 30 & 7 & $1 \sim 6$ & 7 & -20 & 20 \\
\hline
\end{tabular}

\section{RESULTS AND DISCUSSION}

The test apparatus was opened after the experiment and several frost heave cracks were found on the upper surface of the soil sample. In addition, the height of the soil sample reduced $4 \mathrm{~cm}$, which indicate that the freezing-thawing cycle caused settlement. 


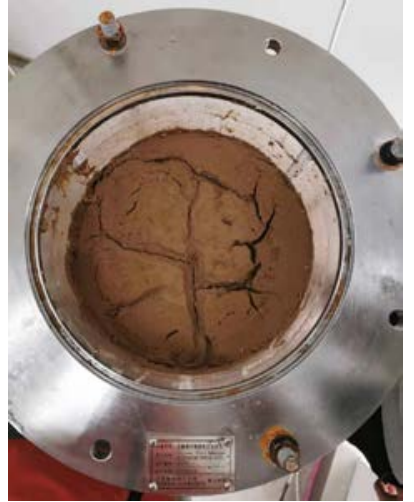

(a) frost heaving cracks

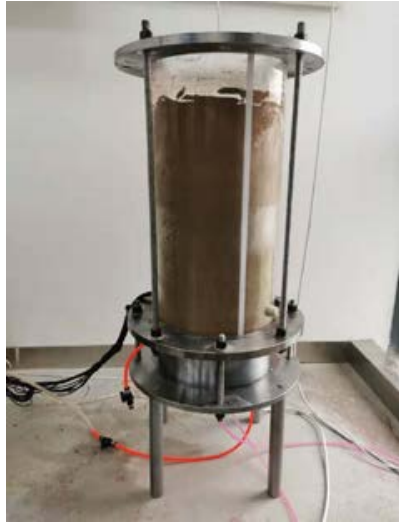

(b) settlement

Fig.4. The soil sample after the test.

Figure 5(a) is temperature profiles of the first 6 days of the test. It can be seen that the temperature reaches stable in 4 days. Figure 5(b) is temperature profile of every six cycles. It shows that the freezing front (namely, $0^{\circ} \mathrm{C}$ line in this paper) gradually moves downward and finally stabilizes at a certain depth. The cause of the moving down of the freezing depth is water redistribution of the soil. The reason why the freezing front reaches stable at last is that the temperature of the lower boundary of the sample is constant.

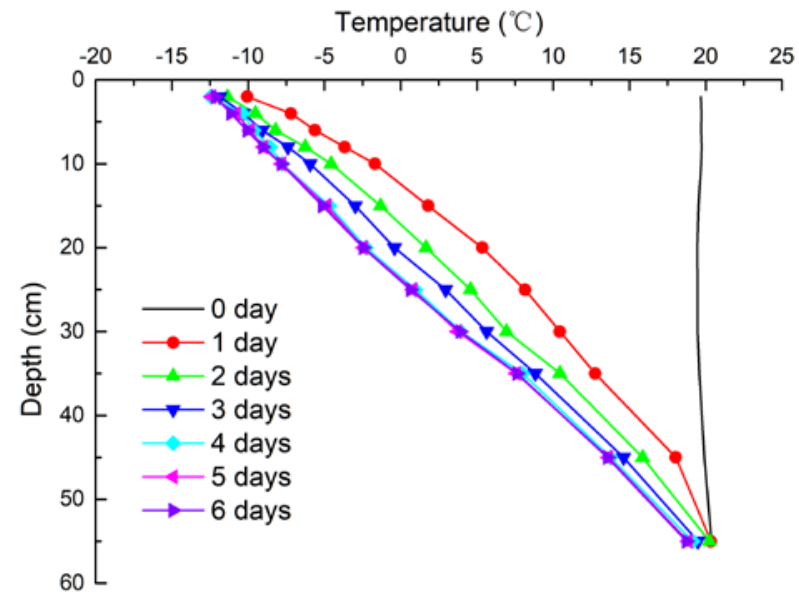

(a) temperature profiles for 1 6 days

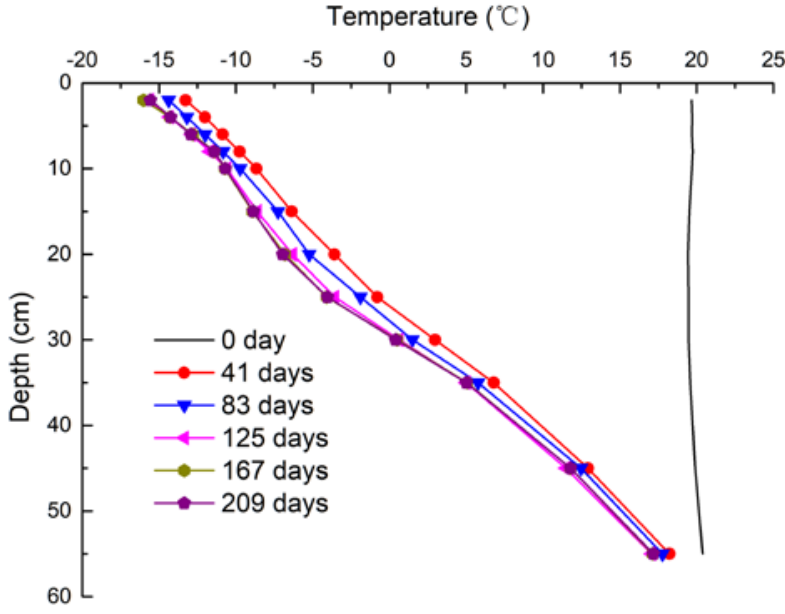

(b) temperature profiles for every 6 cycles

Fig.5. Measured temperature profiles for the unidirectional freezing-thawing cycle test.

Figure 6 is the volumetric water content profiles of the test sample. It can be seen that the water content of the soil sample increase with the increase of unidirectional freezing-thawing cycles. At the end of the test, the water content of the top soil is near liquid limit. The moisture content of the lower part of the soil sample also increased significantly. The average moisture content of soil sample increases $14 \%$, which can lead to obvious decrease of soil strength.

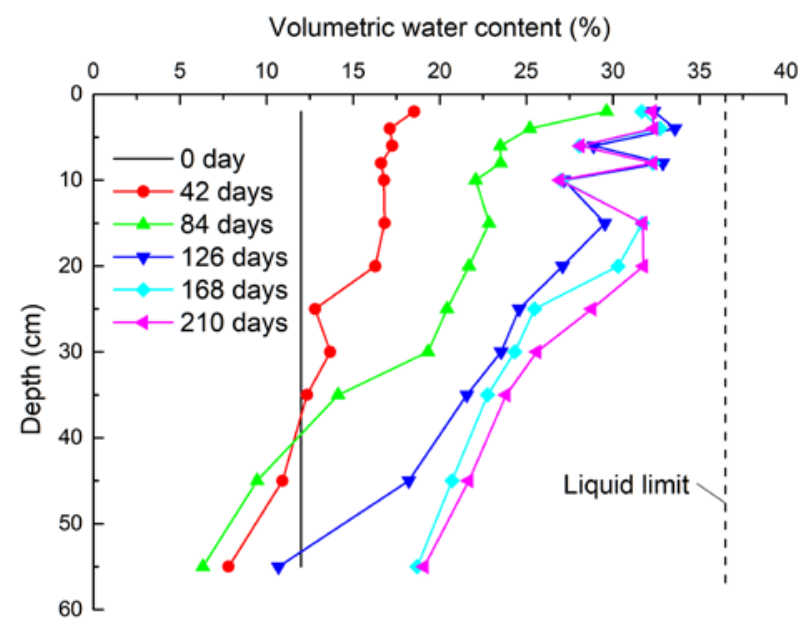

Fig.6. Measured water content profiles for the unidirectional freezing-thawing cycle test.

Figure 7(a) is the water increase of soil of each cycle. It shows that the amount increases firstly and decrease then. The water increase reaches a peak value at about the 15th cycle. The water increases of the last several cycles decrease gradually and the amount of the $30^{\text {th }}$ cycle is 0 . It can be inferred that the water content won't change if the unidirectional freezing-thawing cycle went on, which indicates that there is an equilibrium state of soil moisture under every certain temperature control mode. The law reflected by 
cumulative water increase of soil (Figure 7(b)) consistent with Figure 7 (a).

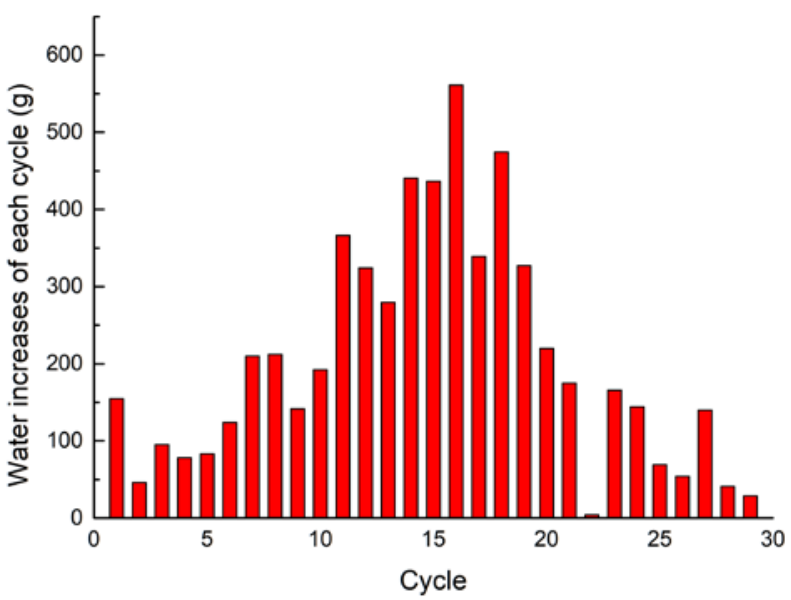

(a) water increases of each cycle

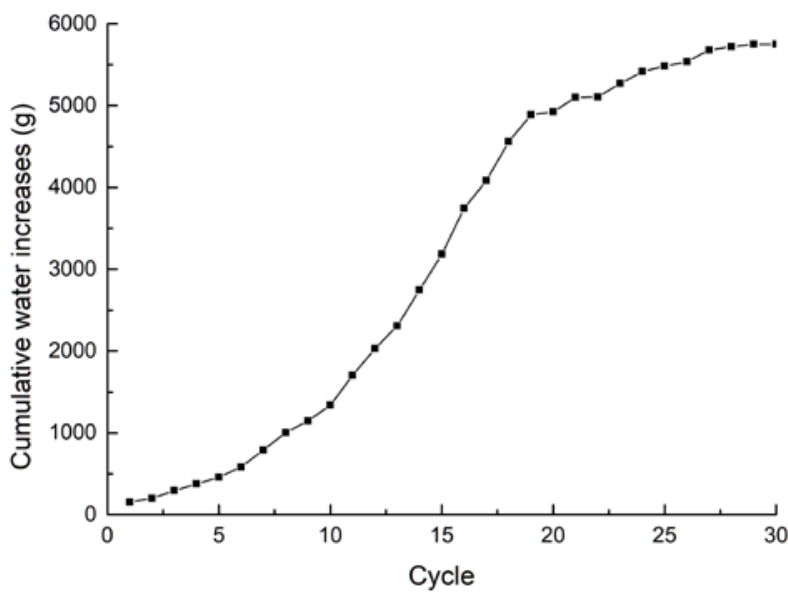

(b) cumulative water increases

Fig.7. The amount of water increases for the unidirectional freezing-thawing cycle test.

\section{CONCLUSIONS}

An experiment with 30 unidirectional freezing-thawing cycles were carried out on silty clay samples to study the vapor transfer law of Pot-cover Effect. The key conclusions of the experiment are listed as follows.

(1) The moisture of the soil sample increases significantly and the water content of the top soil reaches nearly liquid limit after 30 freezing-thawing unidirectional cycles.

(2) With the increase of unidirectional freezing-thawing cycles, the freezing front gradually moves downward and finally stabilizes at a certain depth, which indicates that freezing-thawing cycle can expand the freezing zone of soil.

(3) With the increase of unidirectional freezing-thawing cycles, the amount of water increase of each cycle increases firstly and decreases then. After a certain number of freeze-thaw cycles, the soil moisture reaches an equilibrium state.

\section{ACKNOWLEDGEMENTS}

This study was supported by the National Natural Science Foundation of China (Grants Nos. 51979001 and 11672015), the National Program on Key Basic Research Project of China (973 Program, Grant No. 2014CB047000).

\section{REFERENCES}

1) Luo, T., Qu, X., Wang, N. D., Chen, H. and Yao, Y. P. (2019): Pot cover effect and its prevention: An experimental study in the field, Cold Regions Science and Technology. https://doi.org/10.1016/j.coldregions.2019.102845

2) Yao, Y. P., Hou, W. and Zhou, A. N. (2009): UH model: three-dimensional unified hardening model for overconsolidated clays, Geotechnique, 59(5), 451-469.

3) Yao, Y. P., Sun, D. A. and Matsuoka, H. (2008): A unified constitutive model for both clay and sand with hardening parameter independent on stress path, Computers and Geotechnics, 35(2), 210-222.

4) Yao, Y. P., Yamamoto, H. and Wang, N. D. (2008): Constitutive model considering sand crushing, Soils and Foundations, 48(4), 603-608.

5) Yao, Y. P. and Zhou, A. N. (2013): Non-isothermal unified hardening model: a thermo-elasto-plastic model for clays, Geotechnique, 63(15), 1328-1345.

6) Gao, Z. W., Zhao, J. D. and Yao, Y. P. (2010): A generalized anisotropic failure criterion for geomaterials, International Journal of Solid and Structures, 47, (22-23), 3166-3185.

7) Sun, D. A., Sheng, D. C. and Sloan, S. W. (2007): Elastoplastic modeling of hydraulic and stress-strain behavior of unsaturated soils, Mechanics of Materials, 39(3), 212-221.

8) Sun, D. A., Sheng, D. C., Cui, H. B. and Sloan, S. W. (2007): A density-dependent elastoplastic hydro-mechanical model for unsaturated compacted soils, International Journal for Numerical and Analytical Methods in Geomechanics, 31(11), 1257-1279.

9) Yao, Y. P. and Wang, L. (2018): Double pot cover effect in unsaturated soils. Acta Geotechnica. https://doi.org/10.1007/s11440-018-0705-y

10) Luo, T., Chen, H., Yao, Y. P., Wang, N. D. and Qu, X. (2019): Development of pot-cover effect apparatus with freezing-thawing cycles. Science China Technological Sciences. https://doi.org/10.1007/s11431-018-9482-1

11) Zhang, S., Teng, J. D., He, Z. Y., Liu, Y., Liang, S., Yao, Y. P. and Sheng, D. C. (2016): Canopy effect caused by vapour transfer in covered freezing soils. Géotechnique. 66, 927-940.

12)Teng, J. D., Shan, F., He, Z. Y., Zhang, S., Zhao, G. and Sheng, D. C. (2019): Experimental study of ice accumulation in un-saturated clean sand. Géotechnique. 69, 251-259. 